\title{
Especificação de uma ontologia de convergência entre a formação e atuação dos professores do Sistema e-TEC
}

\author{
Beatriz Wilges, UFSC, beaw@inf.ufsc.br \\ Juliana Leonardi, UFSC, leonardiadm@gmail.com \\ Araci Hack Catapan, UFSC, aracihack@gmail.com \\ Silvia Modesto Nassar, UFSC, silvia@inf.ufsc.br \\ Rogério Cid Bastos, UFSC, rogerio@inf.ufsc.br
}

\begin{abstract}
Resumo: Nesta pesquisa analisam-se os dados cadastrais do curso de formação dos professores que atuam no ensino técnico profissionalizante do Sistema e-TEC Brasil. A proposta é construir uma ontologia capaz de responder a questões sobre a convergência entre a formação e a atuação dos professores. Para isso, implementou-se um sistema de apoio à formação continuada que responde a questões específicas sobre a necessidade ou não de oferecer cursos de aprimoramento dentro de um projeto de capacitação e formação continuada para uma atuação mais adequada e alinhada aos atuais projetos pedagógicos da área de atuação de cada professor. Neste trabalho são relatadas as análises e os detalhes da modelagem da ontologia, bem como o sistema de apoio à formação continuada proposto. Os resultados preliminares têm apontado eficientemente as áreas que devem ter uma atenção e monitoramento mais adequado para a construção de um curso EaD que atenda as demandas do mercado.
\end{abstract}

Palavras-chave: Ontologia, formação de professores, atuação no ensino.

Abstract: This research analyzes the data of the training of teachers who work in technical education e-TEC System. The purpose of this research is to build an ontology which is able to answer questions about the convergence between training and the field of expertise of teachers. Thus, we implemented a support system for continuing education that tries to answer specific questions about whether or not to offer courses to improve within a project for training and continuing education for a more appropriate acting, aligned with current educational projects in the field of each teacher. This paper reports the details of the analysis and the modeling of the ontology, as well as the support system offered for continuing education. Preliminary results have efficiently pointed out the areas which should have a more appropriate attention and monitoring for the construction of a distance education course that meets the market demands.

Keywords: Ontology, teacher training, field of expertise.

\section{Introdução}

O Sistema Escola Técnica Aberta do Brasil (e-Tec) foi lançado em 2007, visa à oferta de educação profissional e tecnológica a distância e tem o propósito de ampliar e democratizar o acesso a cursos técnicos de nível médio, públicos e gratuitos, em regime de colaboração entre União, estados, Distrito Federal e municípios. Os cursos são ministrados por instituições públicas. O Ministério da Educação (MEC) é responsável pela assistência financeira na elaboração dos cursos. Aos estados, Distrito Federal e municípios cabe providenciar estrutura, equipamentos, recursos humanos, manutenção das atividades e demais itens necessários para a instituição dos cursos (BRASIL, 2011). 
Ao longo de 2007 e no primeiro semestre de 2008, especialistas de todo o país, além de representantes dos sistemas de supervisão de ensino dos estados, juntamente com representantes de outros órgãos do governo, somaram esforços ao MEC para elaborar o Catálogo Nacional de Cursos Técnicos (CNCT) com o objetivo de orientar estudantes e instituições de ensino na oferta de cursos técnicos. O catálogo agrupa os cursos conforme suas características científicas e tecnológicas em 12 eixos tecnológicos, que somam ao todo 185 possibilidades de oferta de cursos técnicos (BRASIL, 2009).

Desde 2008, a Universidade Federal de Santa Catarina (UFSC) atua junto ao MEC com projetos de extensão e parceria denominados: Comissão de Validação e Acompanhamento de Materiais Didáticos (CVMD) e Capacitação em Gestão e Docência em EaD. Nesses projetos a UFSC tem o objetivo de oferecer cursos de capacitação aos professores-autores para elaboração de materiais didáticos, além de cursos específicos aos professores-formadores que utilizaram o material didático e aos gestores que administram o sistema. Particularmente a CVMD da UFSC atua nas instituições credenciadas para produção de materiais didáticos para a Educação a Distância (EaD) em dois eixos tecnológicos: Informação e Comunicação (I\&C), e Hospitalidade e Lazer (H\&L).

O eixo de Hospitalidade e Lazer, de acordo com o CNCT (BRASIL, 2009) compreende tecnologias relacionadas aos processos de recepção, viagens, eventos, serviços de alimentação, bebidas, entretenimento e interação. São traços marcantes da organização curricular desses cursos: ética, educação ambiental, normas técnicas e de segurança, historicidade, empreendedorismo, redação técnica, além da capacidade de trabalhar em equipes, com iniciativa, criatividade e sociabilidade. $\mathrm{O}$ eixo de Informação e Comunicação compreende tecnologias relacionadas à comunicação e processamento de dados e informações. Ressalte-se que a organização curricular desses cursos contempla estudos sobre ética, raciocínio lógico, empreendedorismo, normas técnicas e de segurança, redação de documentos técnicos, educação ambiental, formando profissionais que trabalhem em equipes com iniciativa, criatividade e sociabilidade.

Os curso de capacitações promovidas pela UFSC entre 2008 e 2011 habilitaram 370 professores-autores; 436 professores-formadores e 291 gestores, de diversas instituições de diferentes estados brasileiros, que atuam em cursos de Educação Profissional Técnica em EaD nos diferentes eixos detalhados no CNCT. Este artigo analisa os dados dos profissionais que atuam nos cursos dos eixos Hospitalidade e Lazer e Informação e Comunicação.

Sob esse aspecto, observou-se a necessidade de analisar de que maneira a formação desses professores-autores e professores-formadores converge na sua atuação pedagógica sob a ótica dos eixos tecnológicos em questão e em função dessa análise construir um sistema baseado em uma ontologia capaz de responder se há ou não necessidade de formação continuada a esses professores e identificar qual seria essa formação.

A palavra "ontologia", que na filosofia denota uma teoria sobre a natureza do ser ou existência, em Inteligência Artificial (IA) pode ser interpretada como um conjunto de entidades com suas relações, restrições, axiomas e vocabulários. Uma ontologia define um domínio, ou, mais formalmente especifica uma conceitualização acerca de um domínio (Gruber, 1995). De acordo com Clark (1999), normalmente uma ontologia é organizada em hierarquias de conceitos (ou taxonomias), pelo fato de não refletirem nenhum formalismo específico e de representarem com frequência um vocabulário 
comum entre usuários e sistemas. Pode-se considerar as ontologias como a materialização do nível de conhecimento.

Neste trabalho elabora-se uma ontologia para um sistema de apoio à formação dos professores. Segundo Bernardo (2004), a formação de professores vem assumindo uma posição de destaque nas discussões relativas às políticas públicas. É uma preocupação que se evidencia nas reformas que vêm sendo implementadas na política de formação docente bem como nas investigações e publicações da área e nos debates acerca da formação inicial e continuada dos professores. Nessas dimensões, a formação continuada aparece associada ao processo de melhoria das práticas pedagógicas desenvolvidas pelos professores em sua rotina de trabalho e em seu cotidiano escolar.

Para Freire (1996), a prática docente, enquanto dimensão social da formação humana requer sua inclusão num movimento permanente de procura que rediscuta a curiosidade ingênua e a crítica, tornando-se epistemológica. Assim, formar é muito mais do que treinar no desempenho destrezas. Educar "não é transferir conhecimento, mas criar possibilidades para a sua produção ou a sua construção" (FREIRE, 1996, p.25).

A formação, inclusive a dos profissionais da educação, assume um caráter permanente. Freire (1996, p.27), assinala que "quanto mais criticamente se exerce a capacidade de aprender tanto mais se desenvolve epistemologicamente na produção de conhecimento, na construção e reconstrução do saber".

Ainda de acordo com estudos realizados pela Fundação Carlos Chagas (FCC, 2011), a formação continuada é central para o desenvolvimento subjetivo e profissional dos professores e faz parte de um projeto pessoal, como uma escolha necessária para que se possa dar sentido e valor à atividade docente.

Na próxima seção mostra-se como foram analisados os dados sobre formação e experiência dos professores para construção da ontologia. Na terceira seção apresenta-se a ontologia elaborada a partir das análises realizadas e a interface do sistema de apoio proposto para consulta. Ao final relatam-se as conclusões e recomendações para os trabalhos futuros desta pesquisa.

\section{Análises dos dados de formação e atuação dos professores}

No período entre 2008 e 2011, a UFSC capacitou 706 professores de em 58 instituições integradas ao sistema e-Tec Brasil nos seguintes estados: AC, AM, CE, ES, GO, MA, MG, MS, MT, PA, PE, PI, PR, RJ, RR, RS, SC, SE, SP, TO e DF. A Figura 2 e Figura 3 mostram um retrato das instituições capacitadas em sua totalidade por estados e especificadas por região no projeto CVMD no período de 2010 e 2011.

Conforme definição do CNCT os cursos técnicos são associados segundo suas características científicas e tecnológicas em função dos 12 eixos tecnológicos. A Figura 1 apresenta por região e estado, as instituições nas quais os professores foram capacitados pela UFSC, incluindo tanto professores-autores como professoresformadores. 


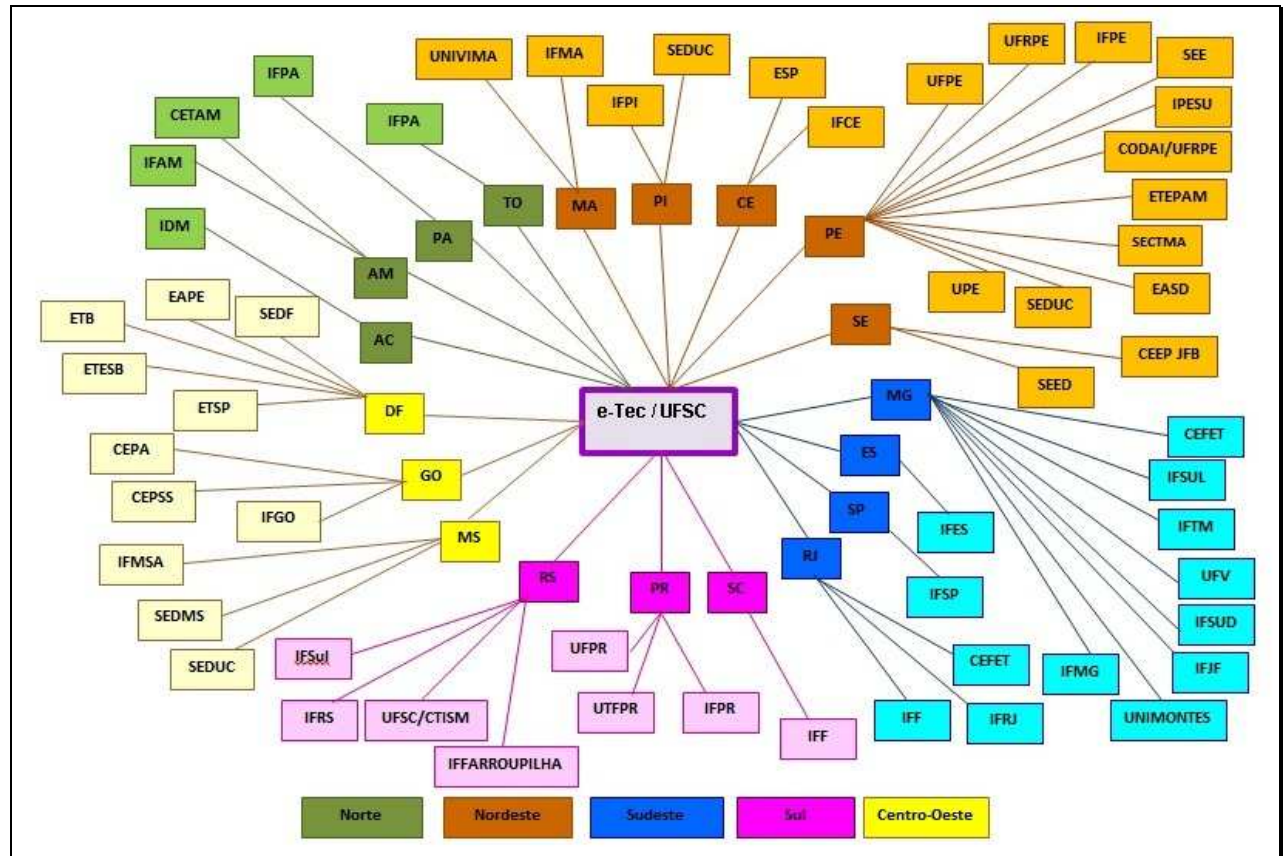

Figura 1 - Instituições capacitadas por região e estado no projeto UFSC/e-Tec

Na Figura 2 destacam-se os eixos de Hospitalidade e Lazer (H\&L) e Informação e Comunicação ( $I \& C$ ) em função de serem eles os eixos de atuação dos projetos, que além de capacitar, analisam diretamente os materiais desenvolvidos. Por essa razão e pela gama de dados disponíveis, este trabalho teve o foco na concepção da ontologia proposta com escopo apenas nesses dois eixos.

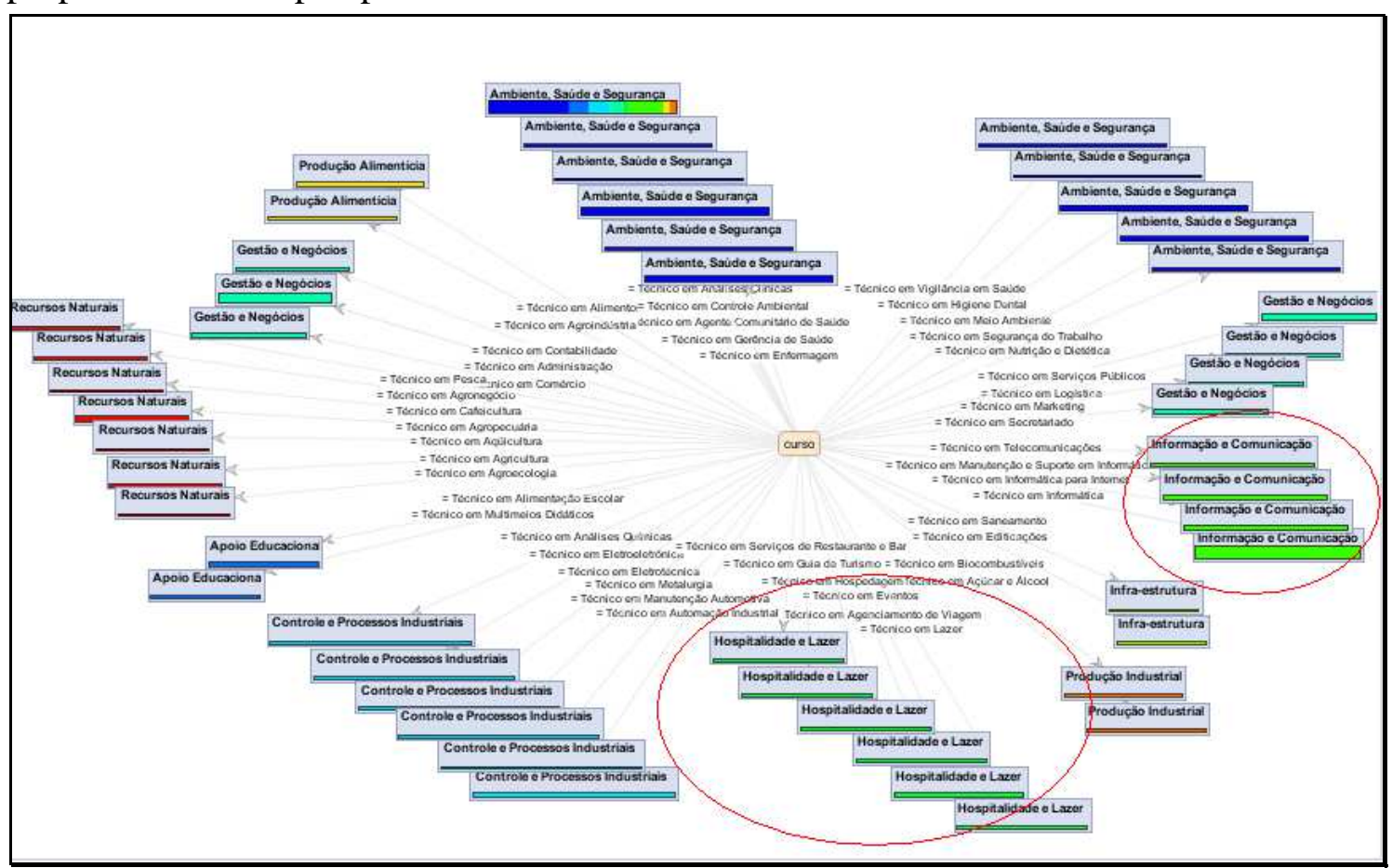

Figura 2 - Escopo dos 12 eixos e seus cursos no projeto CVMD

A Figura 3 apresenta de forma distinta as diferentes formações (no centro) e atuação (nas pontas) dos professores do eixo de Informação e Comunicação. Para 
construção desses mapas analíticos foi utilizada a ferramenta RapidMiner com algoritmo de árvore de decisão ID3 em uma Base de Dados (BD) com a participação de 511 professores.

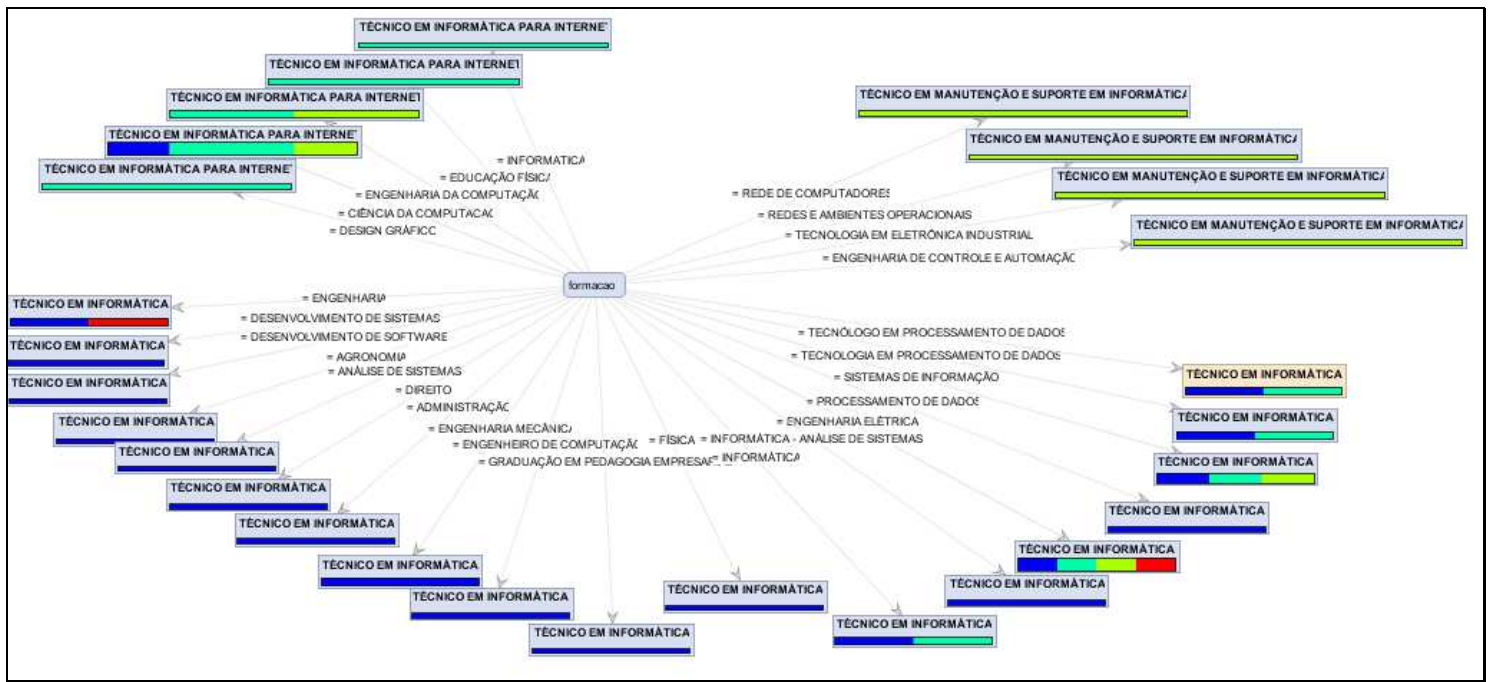

Figura 3 - Formação e atuação nos cursos técnicos no eixo IC

Na Figura 4 são apresentados dados da formação (no centro) e atuação (nas pontas) dos professores no eixo HL. A partir da análise de formação e atuação desses professores nesses dois eixos, construímos uma ontologia que pudesse responder, em um sistema de apoio à formação continuada qual curso de capacitação seria necessário para uma melhor atuação do professor no curso.

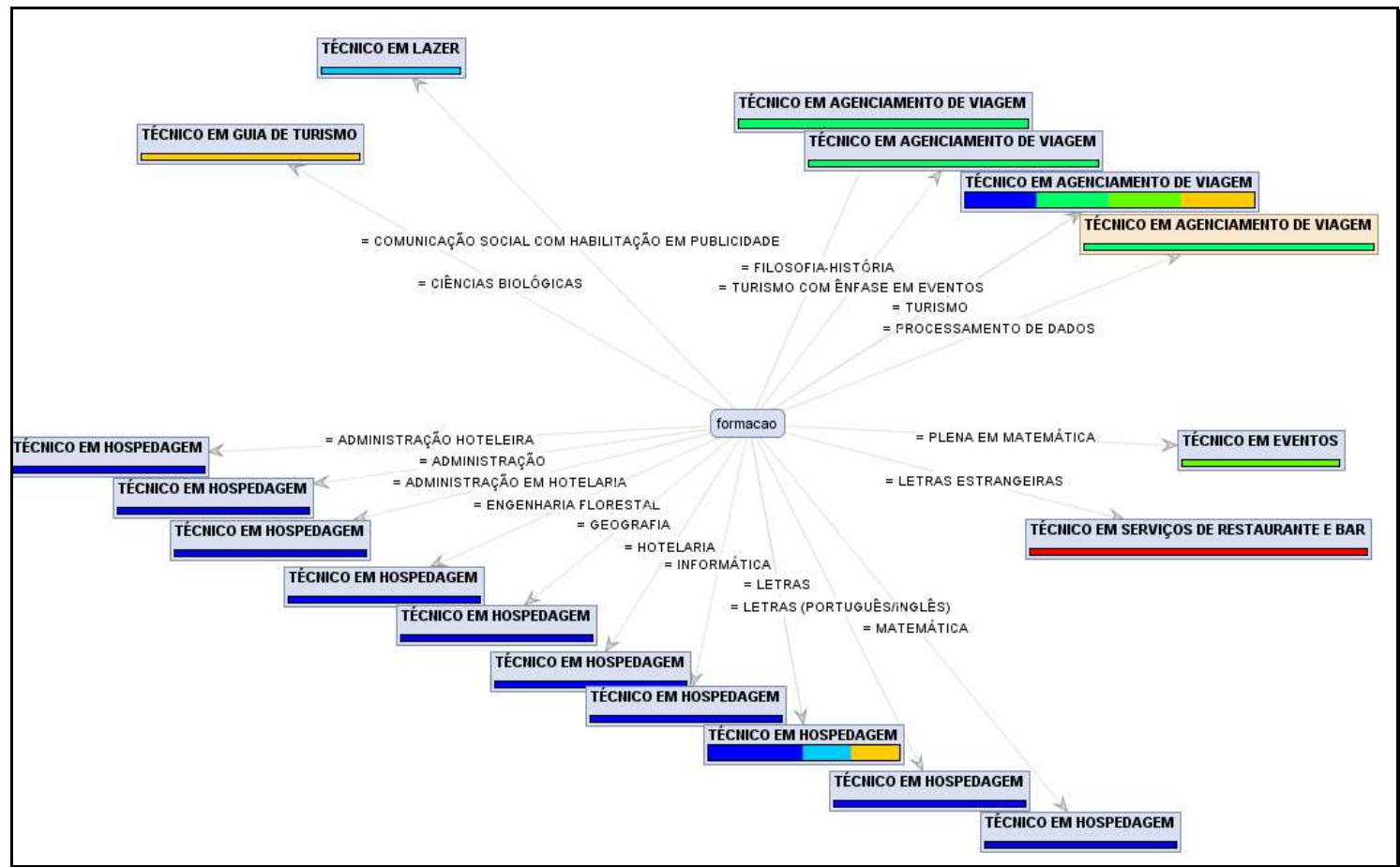

Figura 4 - Formação e atuação nos cursos técnicos no eixo HL 
Os dados da formação e atuação dos professores observados nas Figuras 3 e 4 foram obtidos nos níveis de bacharelado e licenciatura, sem considerar especializações, mestrado e doutorado para ambos os eixos.

\section{A concepção da ontologia}

A partir das análises apresentadas na seção anterior, observou-se que nem sempre existe uma convergência entre a atuação e a formação e por isso considerou-se conveniente e oportuno modelar uma ontologia capaz de apontar caminhos para uma formação continuada desses professores.

As ontologias possuem diferentes classificações que variam de acordo com seu grau de genericidade (GÓMES-PEREZ, 1999). Elas podem ser classificadas como ontologias de representação, gerais, centrais, de domínio, de aplicação, de tarefa. A ontologia proposta neste trabalho mescla a de domínio com a de aplicação, porque procura solucionar um problema específico de um domínio. Ou seja, busca respostas para a formação continuada de professores dentro dos domínios/eixos de I\&C e H\&L. A Figura 5 apresenta um esboço da ontologia gerada a partir das análises realizadas.

\begin{tabular}{|l|}
\hline SUBCLASS EXPLORER \\
For Project: formacao_atuacao \\
Asserted Hierarchy \\
owl:Thing \\
Formacao \\
HospitalidadeLazer \\
InformacaoComunicacao
\end{tabular}

Figura 5 - Esboço da ontologia

Nessa ontologia foram construídas três classes base: Formacao, HospitalidadeLazer, InformacaoComunicacao. A classe Formacao foi construída com base nas formações dos professores presentes no Banco de Dados (BD) e análises das Figuras 3 e 4. Para a construção dessa classe foram utilizadas as definições de grandes áreas presentes em um documento da Comissão Especial de Estudos CNPq, CAPES, FINEP (2005). Nesse documento são consideradas nove grandes áreas, que estão presentes na ontologia, conforme a Figura 6 (esquerda). 
A Figura 8 ilustra a classe HospitalidadeLazer também com os cursos de atuação dos professores e as classes de formação continuada base e completa. A subclasse de formação continuada dentro da classe HospitalidadeLazer foi baseada na descrição no CNCT por Oliveira J. C. (2011).

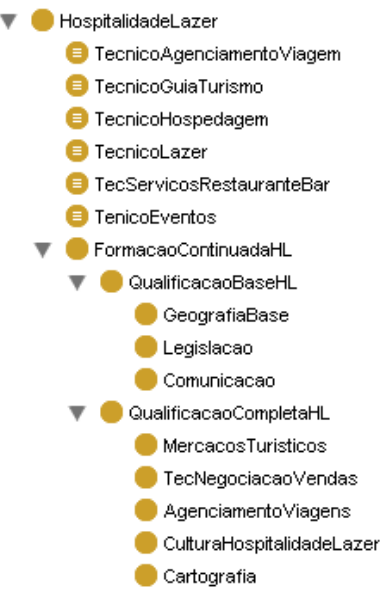

Figura 8 - Classe HospitalidadeLazer

As restrições e axiomas da ontologia foram definidos com base nas classes e em quatro propriedades: FormacaoContinuada, FormacaoBase, AtuacaoEm e FormacaoDesejavelEm. O range da propriedade FormacaoContinuada ficou dentro das subclasses FormacaoContinuadaIC e FormacaoContinuadaHL. O range das propriedades FormacaoBase e FormacaoDesejavelEm ficou na classe Formacao. O range para a propriedade AtuacaoEm foram as duas classes InformacaoComunicacao e HospitalidadeLazer. Algumas das restrições elaboradas entre as classes e as propriedades relatadas para o eixo I\&C são apresentadas na Figura 9.

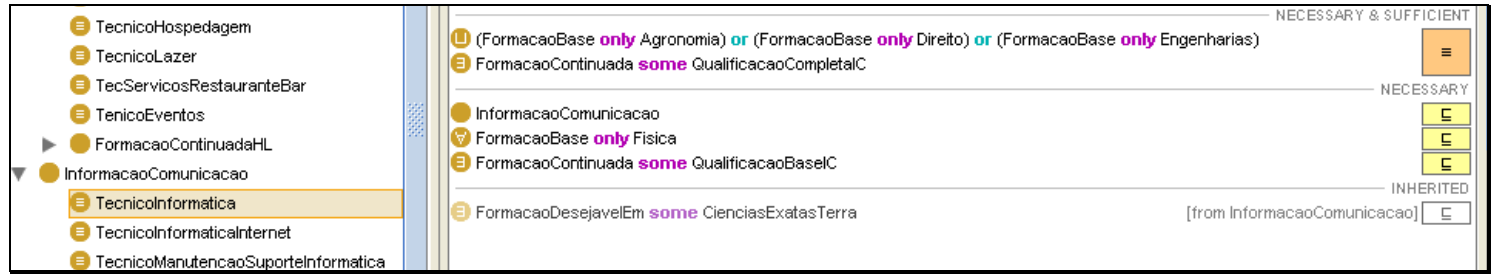

Figura 9 - Restrições do Curso Técnico em Informática

Para cada um dos eixos foram sugeridas as formações nas grandes áreas envolvidas. Ou seja, para o eixo de Informação e Comunicação foi sugerida a área de Ciências Exatas da Terra, conforme é observado na Figura 9. Para o eixo de Hospitalidade e Lazer foi sugerida a grande área de Ciências Sociais Aplicadas (Figura $10)$.

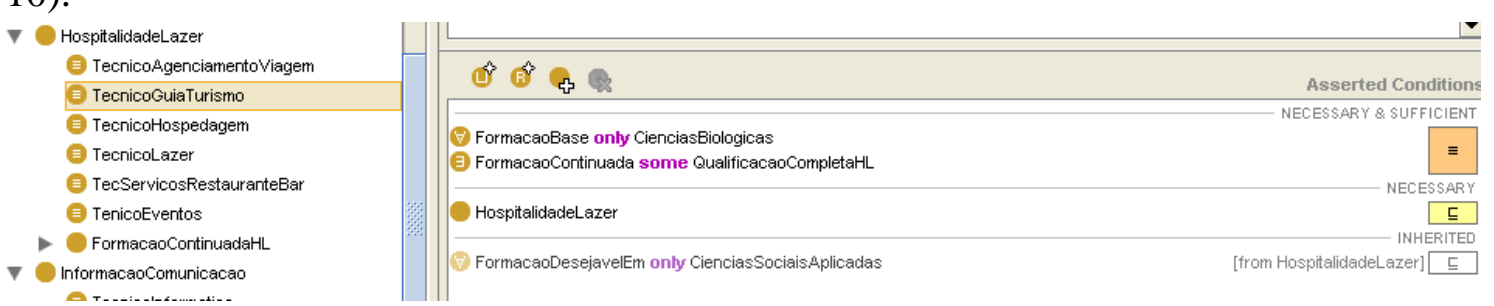

Figura 10 -Restrições do Curso Técnico em Guia de Turismo 
Para elaboração e construção do sistema, a ontologia apresentada foi convertida para o formato RDF, permitindo a manipulação pela Jena, que é uma API Java para manipulação dinâmica de modelos RDFs. A API Jena caracteriza-se por possibilitar a criação e manipulação de grafos RDF, representados pelos recursos (resource), propriedades (properties) e literais, formando as tuplas que dão origem aos objetos criados pelo Java. Assim, esse conjunto de objetos é usualmente chamado de model. $\mathrm{O}$ model pode ser considerado como o conjunto de statements que forma o grafo por completo. O protótipo da interface do sistema de apoio à formação continuada é apresentado na Figura 11.

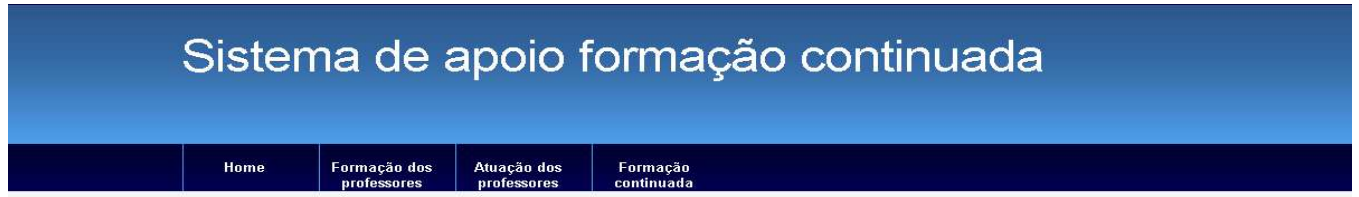

Neste trabalho implementou-se uma ontologia capaz de responder questões sobre a convergência entre a formação e a atuação dos professores.

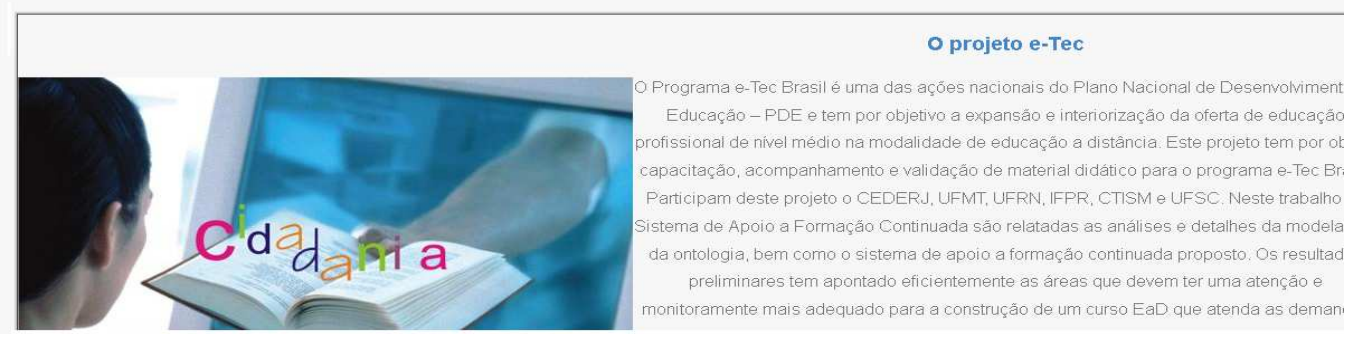

Figura 11 - Interface do sistema de apoio à formação continuada

A API Jena pode ser utilizada na área semântica, propondo codificações e busca de informações nos arquivos RDF dentro do escopo da ontologia elaborada. $\mathrm{O}$ arquivo RDF, normalmente codificado como arquivo XML, é inserido em páginas XHTML, conforme a interface do sistema apresentado na Figura 11. O grafo gerado pela API é obtido através da classe ModelMen que, armazenado em memória, fica disponível até a finalização da execução do programa. Assim, durante essa execução, pode-se percorrer e buscar os elementos da ontologia, fazendo-se as inferências necessárias para consulta.

\section{Conclusões e recomendações}

Os resultados preliminares da ontologia no protótipo do sistema de apoio à formação continuada têm apontado eficientemente as áreas que devem ter uma atenção e monitoramente mais adequados para a construção de um curso EaD que atenda às demandas do mercado.

Segundo Cunha (1989) a formação pedagógica é, para os professores, também fator de influência de seu modo de ser. Ela ocorre de forma diferencial no que se refere a objetivos, filosofia, duração, significado etc. Quanto mais ela responde às necessidades dos professores no momento que a realizam, mais eles a valorizam. Portanto o próximo passo deste estudo será uma análise detalhada dos resultados estendo-se em um elenco de inferências e recomendações. 
Dessa forma, a construção de uma ontologia com base em estudos sobre atuação e formação dos professores pode contribuir para um processo de formação e atualização do quadro de professores de um curso. Além disso, a proposta de trabalhar com a API Jena em uma ontologia RDF permite representar todo conjunto de construtores de conceitos da ontologia, com seus modelos em uma linguagem própria e independente dos construtores de uma linguagem de ontologias em particular.

\section{Referências}

ALVES, H. M. B; RAPOSO, R. O marketing nas universidades: um estudo exploratório sobre a satisfação dos alunos como clientes no ensino superior. Revista Portuguesa de Marketing, v.3, n.8, p. 67-80, 1999.

ANGELL, R. J.; HEFFERNAN, T. W.; MEGICKS, P. Service quality in postgraduate education. Quality Assurance in Education, v.16, n.3, p. 236-254, 2008.

BERNADO, Elisangela da Silva. Um olhar sobre a formação continuada de professores em escolas organizadas no regime de ensino em ciclo(s). 2004. Disponível em: <http://www.anped.org.br/reunioes/27/gt08/t083.pdf>. Acesso em: 10 out. 2011.

BRASIL. Ministério da Educação (MEC). Catálogo Nacional de Cursos Técnicos. 2009. Disponível em: 〈http://catalogonct.mec.gov.br/eixos_tecnologicos.php〉. Acesso em: 15 de nov. 2011.

BRASIL. Ministério da Educação (MEC). Sistema e-Tec Brasil. 2011. Disponível em: $<$ http://portal.mec.gov.br/index.php?option=com_content\&view=article\&id=12326:e-tecapresentacao\&catid=293: escola-tecnica-aberta-do-brasil-e-tec\&Itemid=665> Acesso em: 10 out. 2011.

CLARK, D. 1999. Mad cows, metathesauri, and meaning. IEEE Intelligent Systems, jan./fev. 1999,

CUNHA, Maria Isabel da. O bom professor e sua prática. Campinas, SP: Papirus, 1989.

FREIRE, Paulo. Pedagogia da autonomia: saberes necessários à prática educativa. São Paulo: Paz e Terra, 1996. (Coleção Leitura).

FUNDAÇÃO CARLOS CHAGAS (FCC). Formação continuada de professores: uma análise das modalidades e das práticas em estados e municípios brasileiros. 2011. Disponível em:

<http://www.fvc.org.br/pdf/relatorio-formacao-continuada.pdf〉. Acesso em: 10 out. 2011. (Relatório Final, Estudo realizado pela Fundação Carlos Chagas por encomenda da Fundação Victor Civita).

GÓMEZ-PÉREZ, A. 1999. Tutorial on ontological engineering. Internacional Joint Conference on Artificial Intelligence - IJCAI'1999. Estcolmo, Suécia. Disponível em: <http://www.ontology.org/main/papers/madrid-tutorials.html>. Acesso em: 15 nov. 2011.

GRUBER, Thomas R. Towards principles for the design of ontologies used for knowledge sharing. International Journal of Human and Computer Studies, v. 43, n. 5/6, p. 907-928, ; 1995.

OLIVEIRA, José Ricardo Moraes. Catálogo Nacional de Cursos Técnicos (CNCT). Eixo Tecnológico: Informação e Comunicação. Disponível em:

<http://catalogonct.mec.gov.br/et_informacao_comunicacao/et_informacao_comunicacao.php〉. Acesso em: 20 out. 2011.

OLIVEIRA, Jalinson Costa. Catálogo Nacional de Cursos Técnicos (CNCT). Eixo Tecnológico: Hospitalidade e Lazer. Disponível em:

<http://catalogonct.mec.gov.br/et_hospitalidade_lazer/et_hospitalidade_lazer.php>. Acesso em: 20 out. 2011.

Nova tabela das áreas do conhecimento. Comissão Especial de Estudos CNPq, CAPES, FINEP. Disponível em:<http://www.finep.gov.br/imprensa/sala_imprensa/novatabela.pdf>. Acesso em: 15 nov. 2011

STUDER, R.; BENJAMINS, R.; FENSEL, D. Knowledge engineering: principles and methods. Data and Knowledge Engineering, V. 25, p. 161-197, 1998. 
